\title{
Harmonization of guidelines for the prevention and treatment of cardiovascular disease: the C-CHANGE Initiative
}

\author{
Sheldon W. Tobe MD, James A. Stone MD PhD, Melissa Brouwers PhD, Onil Bhattacharyya MD PhD, \\ Kimberly M. Walker BA, Martin Dawes MD PhD, Jacques Genest Jr MD, Steven Grover MD MPA, \\ Gordon Gubitz MD, David Lau MD PhD, Andrew Pipe MD, Peter Selby MBBS, Mark S. Tremblay MD MSc, \\ Darren E.R. Warburton PhD, Richard Ward MD, Vincent Woo MD, Lawrence A. Leiter MD, Peter P. Liu MD
}

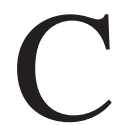
ardiovascular disease is the most prevalent chronic medical condition in Canada, and evidence-based management of risk factors for cardiovascular disease can reduce morbidity and mortality. ${ }^{1}$ However, there are more than 400 individual recommendations for risk management of cardiovascular disease from various guidelines authored or sponsored by many different organizations. Because the guidelines were developed through multiple processes, they use different evidencegrading systems, wording and emphasis (Table $\left.1^{2-4}\right)$. Thus, one can appreciate the challenge for health care providers who are managing the care of patients with, or at increased risk of, atherosclerotic diseases or with multiple comorbidities. Providers must determine which clinical practice guidelines to use, which risk factors to address first and which treatment targets to follow. This challenge created by multiple guidelines inhibits implementation, understanding and adherence, and hinders the delivery of clinically effective guideline-based care. ${ }^{5}$

Without a system in place for harmonization, there is a risk of conflicting recommendations for clinical practice. Even subtle differences in recommendations between guidelines have been identified as barriers to implementation. ${ }^{6}$ For example, based on new evidence, acetylsalicylic acid is no longer routinely recommended for "patients with diabetes without coronary disease," " but it is still recommended in the guidelines of the Canadian Hypertension Education Program for "hypertensive patients without complications." Meanwhile, the guideline for treatment of hypertension from the Canadian Hypertension Education Program recommends the use of a statin for all patients older than 40 years who have hypertension and three risk factors for cardiovascular disease; however, the guideline does not specify the actual treatment targets for low-density lipoprotein cholesterol. ${ }^{8}$ This is in contrast to the guidelines of the Canadian Diabetes Association and the Cana- dian Cardiovascular Society, which include treatment targets. ${ }^{2,3}$ Most of the guidelines include recommendations on exercise, but the recommendations are highly variable in the frequency, intensity, duration and types of exercises recommended. ${ }^{2,8-11}$

The proliferation of conflicting, and often redundant, clinical practice guidelines is not unique to Canada. ${ }^{12}$ Although the problem has been recognized and potential processes to avoid these pitfalls have been suggested,$^{13}$ single organizational approaches have had varied but limited success. ${ }^{14}$ In Canada, clinical practice guidelines have been developed by independent groups with interest in individual risk factors or diseases, usually working with or part of charitable nongovernment health organizations largely dependent on academic and community volunteers. ${ }^{2,48-11,15}$ Clinical practice guidelines often differ in terms of timing of screening, diagnostic approaches, treatment, and the details and descriptions of the foundational evidence that led to recommendations. Development of the guidelines often involves unnecessary duplication of work, such as appraisal of the literature, and exhausts scarce volunteer resources.

\section{KEY POINTS}

- Multiple practice guidelines for similar conditions create challenges because of redundancy, discordance, different priorities for treatment and different evidence bases.

- The C-CHANGE Initiative used a consensus model to harmonize and integrate more than 400 recommendations from eight separate guidelines into 89 key recommendations for the management of cardiovascular risk factors.

- The risk of future cardiovascular events should be determined using established scoring systems in all patients older than 40 years.

- Treatment targets must be based on the individual patient's level of risk.

- Recommended healthy behaviours for all patients include no smoking, following a diet capable of promoting energy balance and a healthy body weight, and adequate weekly physical activity.

- A combination of modifications to health behaviours and pharmacologic interventions will be required in most patients at high and moderate risk of cardiovascular events to meet treatment targets. 


\section{Other efforts to harmonize guidelines}

Harmonization and integration of guidelines is becoming increasingly important for multidisciplinary, interdisciplinary and interprofessional clinical care teams. There have been other efforts worldwide to bring together guidelines for the prevention and treatment of cardiovascular disease. The European Society of Cardiology recognized the complexities of multiple risk factors for cardiovascular disease and developed the SCORE (Systematic Coronary Risk Evaluation) risk stratification program to assess risk factors in a single patient. ${ }^{16}$ Although the European Society of Cardiology published the various individual guidelines together in a single compendium, there appears to have been no process by which the individual guidelines were vetted and harmonized to produce a single set of recommendations.

The US National Institutes of Health is coordinating a similar effort to avoid conflicting recommendations by releasing guidelines together so that they are based on the same set of evidence. The New Zealand cardiovascular guidelines, which were first published in 2003 and had 220 recommendations for global cardiovascular risk management, were reviewed again in 2007..$^{77,18}$ This set of guidelines brought together different risk factors in a single document, adapting other published guidelines for use in New Zealand. The World Health Organization developed Prevention of Cardiovascular Disease: Pocket Guidelines for Assessment and Management of Cardiovascular Risk, ${ }^{19}$ but, to date, these guidelines have not been harmonized or integrated.

Outside the cardiovascular field, harmonized guidelines have been developed for the conduct of clinical trials and good clinical practice. ${ }^{20}$ With regard to evidence-based clinical practice guidelines, however, the concept of harmonization and integration has been discussed, but getting all stakeholders to agree to a common set of principles for implementation has been much more challenging.

\section{The C-CHANGE Initiative}

The C-CHANGE (Canadian Cardiovascular Harmonization of National Guidelines Endeavour) Initiative was developed as a joint community project to create harmonized guidelines. With an aging patient population burdened with multiple chronic diseases, practitioners are challenged to provide the most effective guideline-based medical management for their patients with multiple

Table 1: Challenges of multiple guidelines for risk management of cardiovascular disease

\begin{tabular}{|c|c|c|}
\hline Problem & Example & C-CHANGE approach \\
\hline Redundancy & $\begin{array}{l}\text { There are more than eight different } \\
\text { recommendations for physical activity among } \\
\text { the guidelines }\end{array}$ & $\begin{array}{l}\text { Integrate to a single set of simple } \\
\text { recommendation and remove all } \\
\text { redundancies }\end{array}$ \\
\hline Discordant recommendations & $\begin{array}{l}\text { The Canadian Diabetes Association } \\
\text { recommends target LDL cholesterol levels of } \\
\leq 2.0 \mathrm{mmol} / \mathrm{L} \text {, whereas the Canadian } \\
\text { Cardiovascular Society }{ }^{3} \text { recommends } 50 \% \\
\text { reduction in } \mathrm{LDL} \text { cholesterol levels or levels } \\
<2.0 \mathrm{mmol} / \mathrm{L} \text {, or apolipoprotein B levels } \\
<0.8 \mathrm{~g} / \mathrm{L}\end{array}$ & $\begin{array}{l}\text { Harmonize discrepant recommendations } \\
\text { through review of evidence and consensus } \\
\text { among all guideline developers to maximize } \\
\text { impact and ease of implementation }\end{array}$ \\
\hline Encyclopedic in scope & $\begin{array}{l}\text { Guidelines of the Canadian Hypertension } \\
\text { Education Program }{ }^{4} \text { include detailed } \\
\text { management of pheochromocytoma }\end{array}$ & $\begin{array}{l}\text { Prioritize and simplify to include } \\
\text { recommendations that have broad impact } \\
\text { and influence on outcome }\end{array}$ \\
\hline Different evidence bases & $\begin{array}{l}\text { The Canadian Diabetes Association based its } \\
\text { guidelines on evidence from } 2008 ;^{2} \text { the } \\
\text { Canadian Cardiovascular Society used } \\
\text { evidence from } 2009 ;^{3} \text { and the Canadian } \\
\text { Hypertension Education Program used } \\
\text { evidence from } 2010^{4}\end{array}$ & $\begin{array}{l}\text { Share common evidence-gathering resources } \\
\text { and synchronize formulation of the } \\
\text { guideline }\end{array}$ \\
\hline Different recommendations & $\begin{array}{l}\text { The Canadian Diabetes Association does not } \\
\text { recommend ASA for primary prevention in } \\
\text { people with diabetes; }{ }^{2} \text { the Canadian } \\
\text { Hypertension Education Program does } \\
\text { recommend ASA in people with hypertension }{ }^{4}\end{array}$ & $\begin{array}{l}\text { Provide a common forum to harmonize } \\
\text { recommendations }\end{array}$ \\
\hline $\begin{array}{l}\text { Different implementation } \\
\text { strategies }\end{array}$ & $\begin{array}{l}\text { Approach to lowering blood pressure differs } \\
\text { among guidelines }\end{array}$ & $\begin{array}{l}\text { Adopt the common best-practice strategies } \\
\text { for implementation among all stakeholders }\end{array}$ \\
\hline
\end{tabular}


concurrent comorbidities. ${ }^{21}$ Recent advances in primary care, such as the development of quality indicators ${ }^{22}$ and frameworks for interdisciplinary delivery of care for chronic diseases, attempt to address the same issue of multiple concurrent comorbidities in an individual patient. ${ }^{23}$ This paper describes the harmonized clinical recommendations and the process by which eight distinct groups achieved consensus on the clinical recommendations. The key steps of this process are described below and in Figure 1.

The C-CHANGE Initiative evolved from an ad hoc group of developers of clinical practice guidelines who shared a vision to harmonize their guidelines to meet the needs of primary care practitioners and their patients. The process was slow owing to many barriers and factors, including a lack of an agreed upon methodology, competing academic interests, potential loss of control over individual guidelines processes and a lack of infrastructure to facilitate the volunteer leaders. Building on the principles of other attempts at harmonization of clinical practice guidelines, ${ }^{13,24}$ we brought together the founding members of the C-CHANGE Initiative and set forth the following overarching goals: to establish a common vision and action plan for the prevention and treatment of chronic atherosclerotic disease in Canada; and to develop, disseminate, implement and evaluate a coordinated, harmonized and integrated strategy for the prevention and treatment of cardiovascular disease to help understand cardiovascular risk, treatment targets and treatments to achieve these targets (Box 1).

The harmonized set of recommendations is intended to be consistent, scientifically rigorous and nonredundant, and to positively influence health outcomes. It is hoped that these attributes will facilitate the care of patients with, or at risk of, chronic cardiovascular disease.

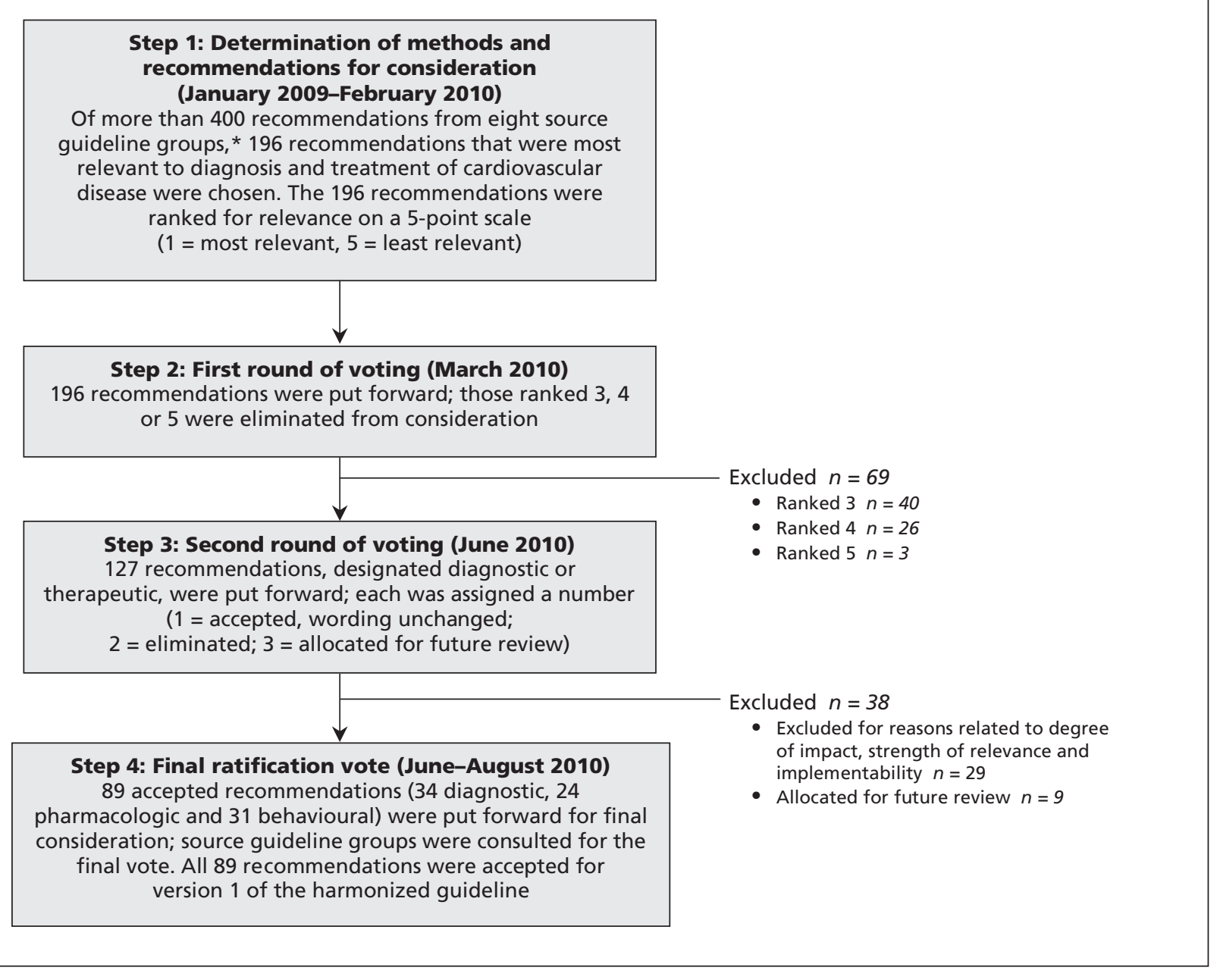

Figure 1: The harmonization process (version 1) of the C-CHANGE (Canadian Cardiovascular Harmonization of National Guidelines Endeavour) clinical practice guidelines. *Canadian Action Network for the Advancement, Dissemination and Adoption of Practiceinformed Tobacco Treatment; Canadian Association of Cardiac Rehabilitation; Canadian Cardiovascular Society Lipid Guidelines; Canadian Diabetes Association; Canadian Hypertension Education Program; Canadian Society for Exercise Physiology; Canadian Stroke Network; Obesity Canada. 


\section{Funding}

The development of harmonized guidelines was funded entirely from public or government sources. The Institute of Circulatory and Respiratory Health at the Canadian Institutes of Health Research provided some unrestricted seed funding to start the C-CHANGE harmonization process, through the institute's knowledge translation program. This was complemented by a contribution grant and in-kind support from staff from the Public Health Agency of Canada. Other public or government sources of funding include Cardiac Care Network of Ontario and Ontario Ministry of Health and Long-Term Care. The funders did not have a direct influence on the process or contents of the recommendations or the preparation of the manuscripts. For complete details, see the funding section at the end of the article.

\section{Methods}

A two-phase methodologic strategy was adopted for the C-CHANGE Initiative. Phase 1 involved building a collaborative relationship among eight core organizations (Canadian Association of Cardiac Rehabilitation; Canadian Cardiovascular Society Lipid Guidelines Group; Canadian Action Network for the Advancement, Dissemination and Adoption of Practice-informed Tobacco Treatment; Canadian Diabetes Association; Canadian Hypertension Education Program; Canadian Society for Exercise Physiology; Obesity Canada; Canadian Stroke Network) that had previously published

Box 1: The C-CHANGE Initiative's strategies for harmonization and integration of clinical practice guidelines

- Develop a standardized database of evidence that is continually updated.

- Review collaborative evidence among national and international organizations.

- Use a common metric to assess the quality of evidence and strength of recommendations.

- Develop clinical practice recommendations concerning issues that are important to patients and clinicians.

- Include relevant stakeholders, with consideration of representatives for patients, on guideline panels.

- Consider comorbidities and the importance of harmonization in the development of guidelines.

- Identify the best tools for implementation for both clinicians and patients.

- Address potential and established conflicts of interest and ensure transparency of sponsorship.

- Maintain a collaboration of national and international organizations.

- Develop methods for effectively establishing clinical outcomes.

- Examine collaborative models for funding the development and implementation of guidelines, such as funded dissemination strategies or licensing of tools adapted for electronic health records.

Note: $\mathrm{C}-\mathrm{CHANGE}=$ Canadian Cardiovascular Harmonization of National Guidelines Endeavour. guidelines, with the goal of producing the first version of the harmonized set of guidelines. Phase 2 will include the development of an integrated review cycle. The goal will be to integrate the methods used by the C-CHANGE Initiative with those of the core guideline groups for developing new and updated recommendations so that there will be coordination and consistency in quality.

In accordance with the AGREE (Appraisal of Guidelines for Research and Evaluation) Collaboration (www.agreecollaboration.org), the CCHANGE Initiative set out to develop a harmonized set of clinical practice recommendations that are informed by evidence, easily implemented, effective in practice, and intended to facilitate surveillance of populations and assessment of outcomes. ${ }^{24,25}$

The eight core guidelines selected for the initial process were chosen because they addressed the key risk factors that contribute to atherosclerotic vascular disease, were national in scope and were supported by major independent national organizations that were free from known third-party bias.

Several approaches - evidence-based recommendations, consensus-based recommendations and expert opinion - were used to ensure that high-quality evidence and buy-in were part of all processes. The evidence-based component ensured that high-quality methods were used to search, select, appraise and synthesize the clinical evidence, with special focus on using the best-quality evidence available. Each of the eight core guidelines was found to be of satisfactory quality when assessed using the AGREE tool by an independent, unbiased evidence-assessment committee. ${ }^{24,25}$

The consensus-based component ensured that the perspectives of all the experts were represented, balanced and acceptable to the development stakeholders and the target user population. The component based on expert opinion ensured that people with the relevant expertise were part of the process. This included content experts with a firm background in scientific and clinical research; those experienced in providing care to the patient population (in this case, primary care specialists, disease-specific specialists and expert allied health care providers); methodologists with expertise in searching, selecting, appraising and synthesizing evidence; and knowledge translation experts with understanding of the knowledge-to-action continuum who could anticipate barriers to implementation. ${ }^{26}$ In these aspects, the C-CHANGE Initiative successfully incorporated a proven evidence-informed approach that incorporated consensus by experts. ${ }^{27}$

Over a period of 12 months, beginning in January 2009, the founding members of the CCHANGE Initiative consulted with representa- 
tives from each of the eight core organizations to determine the appropriate content experts to join the C-CHANGE Guideline Panel. In addition to being content experts, the volunteers selected to join the panel were typically the chairs of the core organizations' guideline panels or played an important role in the development of their guidelines. In addition to guideline experts, primary care practitioners played a pivotal role on the panel. Primary care practitioners participated in the harmonization process to ensure that existing or potential barriers to patient care were avoided in the selection of recommendations.

In February 2010, after a series of meetings, the C-CHANGE Guideline Panel accepted the method of harmonization (Figure 1). It was agreed that in version 1 of the harmonized recommendations, to respect the individual processes of the source guideline groups, the wording of all recommendations chosen would remain unchanged from the source guidelines. No new clinical practice recommendations were drafted or rewritten for version 1. Similarly, no additional assessment of level of evidence or recommendation grade was undertaken at this stage. This approach was necessary to achieve buy-in from all groups. All recommendations being considered for harmonization were chosen based on their relevance to diagnosis (e.g., screening, risk stratification, diagnostic tests), treatment (e.g., therapeutic targets, health behaviour strategies, pharmacologic interventions) and prevention. In the case of diagnostic recommendations, the tests under consideration needed to be linked to long-term morbidity and mortality outcomes. For recommendations related to health behaviour, a surrogate outcome (e.g., lowering of blood pressure) was sufficient. For pharmacologic interventions, high-quality research studies with hard outcomes (e.g., myocardial infarction, stroke and death), assessment of external validity, applicability, clinical relevance and consistency as determined by meta-analyses were required.

\section{Phase I: harmonization process, version 1}

\section{Step 1}

Two members from each core guideline group reviewed their entire set of practice recommendations and, based on relevance to cardiovascular disease, determined a subset of recommendations to be considered in the harmonization process. The result was a total of 196 recommendations, which were ranked according to relevance to the diagnosis, treatment and prevention of cardiovascular disease $(1=$ most relevant, $5=$ least relevant). Of the recommendations, 83 were ranked 1, 44 were ranked 2, 40 were ranked 3, 26 were ranked 4 and 3 were ranked 5 .

\section{Step 2}

The recommendations ranked 3,4 and 5 were excluded. The remaining 127 candidate recommendations were categorized as either diagnostic or therapeutic. Similar recommendations from the different guideline groups were clustered, and the version that was most accurate and simple and best met the needs of health care providers was chosen. Rankings were based on the robustness of the evidence, potential clinical impact on outcomes, and simplicity and implementability in practice. An effort was made to limit recommendations that were based only on consensus opinion. Recommendations based on consensus were considered only when there was no alternative.

\section{Step 3}

The 127 recommendations were individually discussed and reviewed. A minimum of $70 \%$ agreement was needed as a threshold to determine the final set of consensus recommendations. Nine other recommendations were referred back to the core guideline groups for review and update because of new evidence that had become available subsequent to the publication of the core guidelines. Twenty-nine recommendations were excluded for a variety of reasons related to degree of impact, strength of relevance and implementability. This left a list of 89 recommendations (34 diagnostic, 24 pharmacotherapeutic and 31 behavioural) for a final ratification vote.

\section{Step 4}

The 89 recommendations were sent to members of the guideline panel for ratification. Voting required more than $70 \%$ of the panel to support an individual recommendation, and straw polls were used to determine if consensus was going to be possible. All 89 recommendations were ratified by August 2010 and qualified for version 1 of the harmonized guidelines.

\section{Phase 2: integrated review cycle}

Phase 2 aims to integrate the methods of the CCHANGE Initiative with those of the collaborating organizations. The goal will be to have methods for developing, reporting and evaluating clinical practice guidelines that are more consistent with international standards, as outlined in the AGREE II statement. ${ }^{24}$

Future iterations of these harmonized guidelines and practice recommendations will be coordinated with each of the core guideline groups, within the groups' usual reassessment cycles (ranging from one to five years). The eventual goal is to update the harmonized practice recommendations across all clinical practice guidelines 
Box 2: Harmonized recommendations for the diagnosis of cardiovascular disease and associated risk factors (part 1 of 2) Screening strategies

Body habitus

- Height, weight and waist circumference should be measured and body mass index calculated for all adults.

- History and a general physical examination to exclude secondary (endocrine or syndrome-related) causes of obesity and obesityrelated health risks and complications.

- Measuring body mass index $\left(\mathrm{BMI}=\right.$ weight $[\mathrm{kg}] /$ height $\left.[\mathrm{m}]^{2}\right)$ in all adults, and children aged two years and older and adolescents.

- Screening for eating disorders, depression and psychiatric disorders, as appropriate.

- Additional investigations, such as liver enzyme tests, urinalysis and sleep studies (when appropriate), to screen for and exclude other common obesity-related health problems.

Cardiac rehabilitation

- All cardiac rehabilitation patients should be asked at the intake assessment about current and recent levels of alcohol consumption.

- All cardiac rehabilitation patients should undergo screening for active and historical depression and anxiety at the time of the intake assessment.

- All cardiac rehabilitation patients should undergo screening for potential sleep disorders.

- All patients entering cardiac rehabilitation programs should be asked about their smoking status (smoker, former smoker, never smoked, passive smoker) and this should be documented on their health record.

- All patients entering cardiac rehabilitation programs must have a medical assessment and undergo determination of their cardiometabolic fitness prior to the initiation of therapy.

- A directly supervised GXT is recommended as part of the initial cardiac rehabilitation assessment prior to the initiation of therapy.

Coronary artery disease

- In addition to CAD risk assessment, a baseline resting ECG should be performed in: all individuals $>40$ years of age; all individuals with duration of diabetes >15 years; all individuals (regardless of age) with hypertension, proteinuria, reduced pulses or vascular bruits. A repeat resting ECG should be performed every two years in people considered at high risk for CV events.

Diabetes

- All individuals should be evaluated annually for type 2 diabetes risk on the basis of demographic and clinical criteria.

- Screening for diabetes using an FPG should be performed every three years in individuals $\geq 40$ years of age. More frequent and/or earlier testing with either an FPG or a $2 \mathrm{hPG}$ after a 75-g OGTT should be considered in people with additional risk factors for diabetes. These risk factors include: first-degree relative with type 2 diabetes; member of high-risk population (e.g., people of Aboriginal, Hispanic, Asian, South Asian or African descent); history of IGT or IFG; presence of complications associated with diabetes; vascular disease (coronary, cerebrovascular or peripheral); history of gestational diabetes; diabetes mellitus; history of delivery of a macrosomic infant; hypertension; dyslipidemia; overweight; abdominal obesity; polycystic ovary syndrome; acanthosis nigricans; schizophrenia; and other risk factors (see CDA guidelines ${ }^{2}$ ).

- Testing with a $2 \mathrm{hPG}$ after a $75-\mathrm{g}$ OGTT should be undertaken in individuals with an FPG of 6.1 to $6.9 \mathrm{mmol} / \mathrm{L}$ in order to identify individuals with IGT or diabetes.

- Testing with a 2hPG after a 75-g OGTT may be undertaken in individuals with an FPG of 5.6 to 6.0 mmol/L and $\geq 1$ risk factors in order to identify individuals with IGT or diabetes.

Obesity

- Fasting plasma glucose level and determining lipid profile (total cholesterol, triglycerides, LDL-C, HDL-C and TC:HDL-C ratio). Hypertension

- Health care professionals who have been specifically trained to measure blood pressure (BP) accurately should assess BP in all adult patients at all appropriate visits to determine cardiovascular risk and monitor antihypertensive treatment.

Lipid screening

- Screening of the plasma lipid profile is recommended in adult men who are at least 40 years of age, and in women who are at least 50 years of age or postmenopausal.

Smoking cessation

- All patients/clients should be asked if they use tobacco and should have their tobacco use status documented on a regular basis.

Stroke and stroke rehabilitation

- All persons at risk of stroke should have their blood pressure measured at each health care encounter, but no less than once annually.

- Persons at risk of stroke and patients who have had a stroke should be assessed for vascular disease risk factors and lifestyle management issues (diet, sodium intake, exercise, weight, smoking and alcohol intake). They should receive information and counselling about possible strategies to modify their lifestyle and risk factors.

\section{Diagnostic strategies}

Hypertension

- Routine laboratory tests that should be performed for the investigation of all patients with hypertension include: urinalysis; blood chemistry (potassium, sodium and creatinine); fasting blood glucose; fasting serum total cholesterol and high density lipoprotein cholesterol, low density lipoprotein cholesterol and triglycerides; and standard 12-lead electrocardiography. 


\section{Box 2: Harmonized recommendations for the diagnosis of cardiovascular disease and associated risk factors (part 2 of 2)}

- Patients with hypertension and evidence of heart failure should have an objective assessment of left ventricular ejection fraction, either by echocardiogram or nuclear imaging.

- The use of home blood pressure monitoring on a regular basis should be considered for patients with hypertension, particularly those with: diabetes mellitus; chronic kidney disease; suspected nonadherence; demonstrated white coat effect; and blood pressure controlled in the office but not at home (masked hypertension).

\section{Risk stratification strategies}

Cardiac rehabilitation

- All patients entering cardiac rehabilitation programs must have a medical assessment and undergo determination of their cardiometabolic fitness prior to the initiation of therapy.

\section{Diabetes}

- Assessment for coronary artery disease risk should be performed periodically in people with diabetes and should include: CV history (dyspnea, chest discomfort); lifestyle (smoking, sedentary lifestyle, poor eating habits); duration of diabetes; sexual function history; abdominal obesity; lipid profile; blood pressure; reduced pulses or bruits; glycemic control; presence of retinopathy; estimated glomerular filtration rate and random albumin to creatinine ratio; periodic electrocardiograms as indicated.

- The following individuals with diabetes should be considered at high risk for CV events: men aged $\geq 45$ years, women aged $\geq 50$ years; men $<45$ years and women $<50$ years with $\geq 1$ of the following: macrovascular disease (e.g., silent myocardial infarction or ischemia, evidence of peripheral arterial disease, carotid arterial disease or cerebrovascular disease); microvascular disease (especially nephropathy and retinopathy); multiple additional risk factors, especially with a family history of premature coronary or cerebrovascular disease in first-degree relative; extreme level of a single risk factor (e.g., LDL-C > 5.0 mmol/L, systolic $\mathrm{BP}>180 \mathrm{~mm} \mathrm{Hg}$ ); duration of diabetes $>15$ years with age $>30$ years.

Note: $2 \mathrm{hPG}=2$ - $\mathrm{h}$ postchallenge glycemia test, $\mathrm{BMI}=$ body mass index, $\mathrm{C}=$ cholesterol, $\mathrm{CAD}=$ coronary artery disease, $\mathrm{CDA}=\mathrm{Canadian} \mathrm{Diabetes}$ Association, $\mathrm{CV}=$ cardiovascular, ECG = electrocardiogram, FPG = fasting plasma glucose, GXT = graded exercise test, $\mathrm{HDL}=$ high-density lipoprotein, IFG = impaired fasting glycemia, IGT = impaired glucose tolerance, $\mathrm{LDL}=$ low-density lipoprotein, OGTT = oral glucose tolerance test, $\mathrm{TC}=$ total cholesterol .

on an identified cyclical rotation. Ideally, a single group would evolve that would coordinate and implement the harmonized set of guidelines in concert with individual groups. However, the latter would also continue to develop the many specific recommendations relevant to that group, such as the diagnosis and management of pheochromocytoma. In addition, as each guideline group updates its recommendations, they will work with experts in knowledge translation to improve the clarity of each recommendation to make them easier to understand while preserving their scientific accuracy. An example of this type of direct interguideline cooperation is the set of recommendations for managing hypertension in diabetes prepared by the guideline groups of the Canadian Hypertension Education Program and the Canadian Diabetes Association.

\section{The harmonized clinical practice recommendations}

The harmonized recommendations for the diagnosis and treatment of cardiovascular disease are presented in Boxes 2 and 3. They appear as written in their original clinical practice guidelines, and no new practice recommendations were added or created. Because the eight core guidelines used different systems of grading evidence, the levels of evidence and recommendation grades have not been included for reasons of simplicity. Given these inherent differences, the members of the C-CHANGE Initiative felt that inclusion of the categories of the evidence grading systems within the harmonized recommendations themselves would be confusing for most practitioners. However, the specific levels and grades of evidence attached to each recommendation, as well as the clinical practice guideline from which they originated, can be viewed in Appendix 1 (available at www.cmaj.ca/lookup /suppl/doi:10.1503/cmaj.101508/-/DC1).

\section{Screening strategies}

We currently recommend that clinicians screen all people older than 40 years for risk of cardiovascular events using a well-established risk stratification or scoring model (see "Risk stratification strategies") every one to three years, depending on previous risk status. Patients should also be assessed for any current evidence of target-organ damage associated with cardiovascular disease. Patients with a positive family history of cardiovascular disease before age 60 years or those who belong to high-risk ethnic groups (e.g., South Asian) or subpopulations (e.g., people with diabetes) should be assessed more frequently. This same global strategy for assessing risk of cardiovascular disease has been adopted and endorsed by the Canadian Cardiometabolic Risk Working Group. ${ }^{7}$ These risk models for cardiovascular events usually include fasting plasma glucose, blood pressure and a 
Box 3: Harmonized recommendations for the treatment of cardiovascular disease and associated risk factors (part 1 of 3 )

\section{Treatment targets}

Alcohol consumption

- Two or fewer standard drinks per day; fewer than 14 drinks per week for men; fewer than 9 drinks per week for women.

Body habitus

- Maintenance of a healthy body weight (body mass index 18.5 to $24.9 \mathrm{~kg} / \mathrm{m}^{2}$, and waist circumference less than $102 \mathrm{~cm}$ for men and less than $88 \mathrm{~cm}$ for women) is recommended for nonhypertensive individuals to prevent hypertension and for hypertensive patients to reduce blood pressure. All overweight hypertensive individuals should be advised to lose weight.

- Adults with class III obesity (BMI $\geq 40.0 \mathrm{~kg} / \mathrm{m}^{2}$ ) or class II obesity (BMI 35.0 to $39.9 \mathrm{~kg} / \mathrm{m}^{2}$ ) with other comorbidities may be considered for bariatric surgery when other lifestyle interventions are inadequate in achieving weight goals.

- A nutritionally balanced diet (designed to reduce energy intake) should be combined with other supportive interventions to achieve a healthy body weight in overweight and obese people of all ages and to ensure the maintenance of growth in adolescents and youth.

\section{Diabetes}

- Glycemic targets must be individualized; however, therapy in most individuals with type 1 or type 2 diabetes should be targeted to achieve an $A_{1 c}$ of $\leq 7.0 \%$ in order to reduce the risk of microvascular and, in individuals with type 1 diabetes, macrovascular complications.

- A target $A_{1 c}$ of $\leq 6.5 \%$ may be considered in some patients with type 2 diabetes to further lower the risk of nephropathy, but this must be balanced against the risk of hypoglycemia and increased mortality in patients who are at significantly elevated risk of cardiovascular disease.

\section{Health behaviour interventions}

\section{Diet}

In all adults

- Healthy balanced diet: high in fresh fruits, vegetables, low-fat dairy products, dietary and soluble fibre, whole grains and protein from plant sources and low in saturated fat, cholesterol and sodium, in accordance with Canada's Food Guide to Healthy Eating. ${ }^{28}$

- Sodium: the recommended daily sodium intake from all sources is the adequate intake by age. For persons 9-50 years, the adequate intake is $1500 \mathrm{mg}$. Adequate intake decreases to $1300 \mathrm{mg}$ for persons $50-70$ years and to $1200 \mathrm{mg}$ for persons $>70$ years. A daily upper consumption limit of $2300 \mathrm{mg}$ should not be exceeded by any age group.

In hypertension

- For prevention and treatment of hypertension, a dietary sodium intake of $1500 \mathrm{mg}$ (65 mmol) per day is recommended for adults age 50 years or less; $1300 \mathrm{mg}$ ( $57 \mathrm{mmol})$ per day if age 51 to 70 years; and $1200 \mathrm{mg}(52 \mathrm{mmol})$ per day if age greater than 70 years. In diabetes

- Adults with diabetes should consume no more than $7 \%$ of total daily energy from saturated fats and should limit intake of trans fatty acids to a minimum.

- All patients/clients should be asked about their dietary habits on a regular basis and this should be documented on their health record.

- An optimal dietary plan for achieving healthy body weight and dietary counselling for adults should be developed with a qualified and experienced health professional (preferably a registered dietitian) together with the individual and family to meet their needs.

- A nutritionally balanced diet (designed to reduce energy intake) should be combined with other supportive interventions to achieve a healthy body weight in overweight and obese people of all ages.

- A high-protein or a low-fat diet (within acceptable macronutrient distribution ranges indicated in the dietary reference intakes) is suggested as a reasonable short-term (6-12 months) treatment option for obese adults as part of a weight-loss program.

- Meal replacements may be considered as a component of an energy-reduced diet for selected adults interested in commencing a dietary weight-loss program.

\section{Dyslipidemia}

Treatment target is based on the person's risk level.

- High risk: LDL-C $<2.0 \mathrm{mmol} / \mathrm{L}$ or $50 \%$ in LDL-C; alternate target: apoB $<0.80 \mathrm{~g} / \mathrm{L}$.

- Moderate risk: $L D L-C<2.0 \mathrm{mmol} / \mathrm{L}$ or $50 \%$ reduction in $\mathrm{LDL}-\mathrm{C}$; alternate target: apoB $<0.80 \mathrm{~g} / \mathrm{L}$.

- Low risk: if LDL-C $\geq 5.0 \mathrm{mmol} / \mathrm{L}$, reduce $\mathrm{LDL}-\mathrm{C} \geq 50 \%$; apoB $<0.90 \mathrm{~g} / \mathrm{L}$.

Hypertension

- Antihypertensive therapy should be strongly considered if systolic blood pressure readings average $140 \mathrm{~mm} \mathrm{Hg}$ or higher in the presence of macrovascular target organ damage.

- For patients with nondiabetic chronic kidney disease, target blood pressure is $<130 / 80 \mathrm{~mm} \mathrm{Hg}$.

- Persons with diabetes mellitus should be treated to attain systolic blood pressures of less than $130 \mathrm{~mm} \mathrm{Hg}$ and diastolic blood pressures of less than $80 \mathrm{~mm} \mathrm{Hg}$. (These target blood pressure levels are the same as the blood pressure treatment thresholds.)

- Antihypertensive therapy should be strongly considered if diastolic blood pressure readings average $90 \mathrm{~mm} \mathrm{Hg}$ or higher in the presence of macrovascular target organ damage or other independent cardiovascular risk factors. 


\section{Box 3: Harmonized recommendations for the treatment of cardiovascular disease and associated risk factors (part 2 of 3)}

Obesity

- Adults with class III obesity (BMI $\geq 40.0 \mathrm{~kg} / \mathrm{m}^{2}$ ) or class II obesity (BMI 35.0 to $39.9 \mathrm{~kg} / \mathrm{m}^{2}$ ) with other comorbidities may be considered for bariatric surgery when other lifestyle interventions are inadequate in achieving weight goals.

- The initial weight loss goal in obese individuals should be $5 \%$ to $10 \%$ of baseline body weight.

- Primary care health professionals are encouraged to create a nonjudgmental atmosphere when discussing weight management.

- Health care professionals are encouraged to consider the barriers people might have concerning obesity and its management.

- A comprehensive healthy lifestyle intervention is recommended for overweight and obese people.

- All those considering initiating a vigorous exercise program are encouraged to consult their physician or health care team professionals.

- Long-term, regular physical activity is suggested, which is associated with maintenance of body weight or a modest reduction in body weight for all overweight and obese people.

- Physical activity and exercise should be sustainable and tailored to the individual. The total duration should be increased gradually to maximize the weight-loss benefits.

Physical activity

- To achieve health benefits, adults aged 18-64 years should accumulate at least 150 min of moderate-to-vigorous-intensity aerobic physical activity per week, in bouts of 10 min or more.

- It is also beneficial to add muscle- and bone-strengthening activities that use major muscle groups, at least two days per week.

- More physical activity provides greater health benefits.

Smoking cessation

- All smokers should receive nonjudgmental, clear and unambiguous advice to consider making a quit attempt using a clear, personalized message.

- All physicians, nurses and other health care workers should strongly advise all patients who smoke to quit and provide brief advice.

- All patients entering cardiac rehabilitation should be asked about their smoking status (smoker, former smoker, never smoked, passive smoker) and this should be documented on their health record.

Stroke rehabilitation

- Following the acute phase of a stroke, patients should have their blood pressure chronically controlled to a target of less than $140 / 90 \mathrm{~mm} \mathrm{Hg}$.

\section{Pharmacologic therapy}

Diabetes

- As $\beta$-blockers provide similar or enhanced survival benefit in patients with diabetes and Ml compared to patients without diabetes, they should be prescribed and not withheld because of concern about the risks associated with hypoglycemia.

- Unless contraindicated, metformin may be used in people with type 2 diabetes and heart failure.

Dyslipidemia

- LDL therapies. Statin monotherapy is the initial treatment of choice in patients whose LDL level is elevated based on their level of CVD risk (moderate and high-risk patients with $L D L>2.0 \mathrm{mmol} / \mathrm{L}$ or apoB $>0.80$ ).

- HDL therapies. No current pharmacological interventions for increasing HDL are available.

- Triglyceride therapies. In patients with extreme hypertriglyceridemia (> $10.0 \mathrm{mmol} / \mathrm{L}$ ), fibrates may prevent pancreatitis.

- Combination therapies. A minority of patients requiring pharmacologic therapy will require combination therapy (cholestyramine, ezetimibe, niacin, fibrates) to achieve, or move closer to, LDL treatment targets.

Hypertension

- Initial therapy should consist of monotherapy with a thiazide diuretic; a $\beta$-blocker (in patients younger than 60 years); an ACE inhibitor (in nonblack patients); a long-acting CCB; or an ARB. If there are adverse effects, another drug from this group should be substituted. Hypokalemia should be avoided in patients treated with thiazide diuretic monotherapy.

- Additional antihypertensive drugs should be used if target blood pressure levels are not achieved with standard dose monotherapy. Add-on drugs should be chosen from first line choices. Useful choices include a thiazide diuretic or CCB with an ACE inhibitor, ARB or a $\beta$-blocker. Caution should be exercised in combining a nondihydropyridine CCB and a $\beta$-blocker. The combination of an ACE inhibitor and ARB is not recommended.

- $\alpha$-Blockers are not recommended as first-line agents for uncomplicated hypertension.

Hypertension and chronic kidney disease

- Thiazide diuretics are recommended as additive antihypertensive therapy. For patients with chronic kidney disease and volume overload, loop diuretics are an alternative.

Hypertension and diabetes

- Persons with diabetes mellitus should be treated to attain systolic blood pressures of less than $130 \mathrm{~mm} \mathrm{Hg}$ and diastolic blood pressures of less than $80 \mathrm{~mm} \mathrm{Hg}$. Combination therapy using two first-line agents may also be considered as initial treatment of hypertension if systolic blood pressure is $20 \mathrm{~mm} \mathrm{Hg}$ above target or if diastolic blood pressure is $10 \mathrm{~mm} \mathrm{Hg}$ above target. 


\section{Box 3: Harmonized recommendations for the treatment of cardiovascular disease and associated risk factors (part 3 of 3 )}

- For persons with cardiovascular or kidney disease, including microalbuminuria or with cardiovascular risk factors in addition to diabetes and hypertension, an ACE inhibitor or an ARB is recommended as initial therapy.

- For persons with diabetes and hypertension not included in the above recommendation, appropriate choices include (in alphabetical order): ACE inhibitors, angiotensin receptor blockers, dihydropyridine CCBs and thiazide/thiazide-like diuretics. If target blood pressures are not achieved with standard-dose monotherapy, additional antihypertensive therapy should be used For people in whom combination therapy with an ACE inhibitor is being considered, a dihydropyridine CCB is preferable to hydrochlorothiazide.

Hypertension and heart disease

- In patients with systolic dysfunction, an ARB is recommended if ACE inhibitors are not tolerated.

- For hypertensive patients with heart failure whose blood pressure is not controlled, an ARB may be added to an ACE inhibitor and other antihypertensive drug treatment. Careful monitoring should be used if combining an ACE inhibitor and an ARB due to potential adverse effects such as hypotension, hyperkalemia and worsening renal function. Additional therapies may also include dihydropyridine CCBs.

- An ACE inhibitor or ARB is recommended for most patients with hypertension and coronary artery disease.

- In patients with coronary artery disease and deemed to be at high risk, when combination therapy is being used, choices should be individualized. The combination of an ACE inhibitor and a dihydropyridine CCB is preferable to an ACE inhibitor and a diuretic in selected patients.

- For patients with stable angina, $\beta$-blockers are preferred as initial therapy. CCBs may also be used.

- For patients with recent myocardial infarction, initial therapy should include both a $\beta$-blocker and an ACE inhibitor. An ARB can be used if the patient is intolerant of an ACE inhibitor.

Hypertension and stroke

- For patients with stroke, the combination of an ACE inhibitor and ARB is not recommended. Treatment with an ACE inhibitor/ diuretic combination is preferred.

- For the secondary prevention of stroke, patients with atrial fibrillation who have had a stroke/TIA should be treated with warfarin at a target international normalized ratio of 2.5, range 2.0 to 3.0 (target international normalized ratio of 3.0 for mechanical cardiac valves, range 2.5 to 3.5), if they are likely to be compliant with the required monitoring and are not at high risk for bleeding complications.

- Strong consideration should be given to the initiation of antihypertensive therapy after the acute phase of a stroke or transient ischemic attack.

Stroke

- Antiplatelet therapy: all patients with ischemic stroke or transient ischemic attack should be prescribed antiplatelet therapy for secondary prevention of recurrent stroke unless there is an indication for anticoagulation.

- ASA, combined ASA (25 mg) and extended-release dipyridamole (200 mg), or clopidogrel (75 mg) are all appropriate options and selection should depend on the clinical circumstances.

Note: $\mathrm{ACE}=$ angiotensin-converting enzyme, apoB = apolipoprotein $\mathrm{B}, \mathrm{ARB}=$ angiotensin-receptor blocker, $\mathrm{ASA}=$ acetylsalicylic acid, $\mathrm{BMI}=$ body mass index, $\mathrm{CCB}=$ calcium channel blocker, $\mathrm{CVD}=$ cardiovascular disease, $\mathrm{HDL}=$ high-density lipoprotein, $\mathrm{LDL}=$ low-density lipoprotein, $\mathrm{MI}=\mathrm{myocardial}$ infarction,

TIA = transient ischemic attack.

complete lipid profile. The following should also be assessed in all patients: body mass index, tobacco use, alcohol intake, physical activity levels and dietary habits.

\section{Diagnostic strategies}

Several of the guidelines cross-reference each other with regard to diagnostic strategies. ${ }^{7}$ The current recommendations for diagnosing hypertension are the most complete and have been adopted by the C-CHANGE Initiative. These recommendations emphasize the need to screen for all traditional risk factors for cardiovascular disease simultaneously, preferably using a well-recognized risk-stratification tool. This integrated approach is true to the principles of the C-CHANGE Initiative.

\section{Risk-stratification strategies}

Although the harmonized recommendations emphasize the need to base decisions about inter- ventions on the patient's level of cardiometabolic risk, there is no consensus at the moment regarding which is the best calculator for determining that risk. Therefore, the C-CHANGE Initiative has neither endorsed nor recommended any specific risk-stratification tool.

Multiple validated risk engines are available, and they are all generally useful in separating patients into categories of low, intermediate and high risk. ${ }^{29-32}$ An in-depth discussion of the pros and cons of each of these risk-scoring systems for cardiovascular events, both singularly and comparatively, is beyond the scope of this article, and interested readers are referred to excellent reviews on this subject. ${ }^{33,34}$ There are, however, a number of general concepts and principles regarding risk-scoring systems that are worthy of highlighting.

First is the concept that most risk-stratification systems for cardiovascular disease do not 
predict the presence of disease but rather the future risk of disease-related events. ${ }^{35}$ People at high risk of cardiovascular events almost uniformly have evidence of atherosclerosis, but a substantial minority of people at low predicted risk will also have objective evidence of atherosclerosis. ${ }^{36}$ Thus, clinicians, and their patients, need to understand that risk-prediction or riskdetermination systems for cardiovascular disease predict the risk of an event, not the risk of disease. Indeed, this disconnect between the level of risk for a cardiovascular event and the presence of asymptomatic atherosclerosis may help to explain at least in part the imperfect clinical performance of prediction systems.

Second, risk-determination systems reflect global risk from exposure to risk factors for cardiovascular disease. ${ }^{37,38}$ This means that the cumulative effect of all of a person's risk factors for cardiovascular disease will almost always outweigh the adverse effects of a single risk factor, even one that is very abnormal. Consequently, patients should be assessed for all of their risk factors for cardiovascular disease.

Third, the performance of any single prediction system for cardiovascular events depends on the particular discrimination, calibration and reclassification abilities of the model in question. Discrimination is the ability to clearly separate patients who will experience a cardiovascular event from those who will not. Calibration refers to how closely predicted cardiovascular events agree with actual outcomes going from one study population to another. Reclassification refers to the ability of a risk model or prediction system to determine whether a person's risk for a cardiovascular event is increased or decreased based on ever-changing evidence of risk. People with a particular risk for cardiovascular events identified by one of the usual prediction models for cardiovascular disease may be subsequently reclassified to higher- or lower-risk groups depending on the presence or absence of systemic atherosclerosis as identified by imaging modalities. ${ }^{36}$

The ideal attributes of common risk-prediction models for cardiovascular events are presented in Table 2. However, within the continuum of risks for cardiovascular events, people with low intensity of risk (i.e., a low-risk profile for cardiovascular events) may still have adverse cardiovascular events if they have high susceptibility (genetic predisposition) to those risk factors. Conversely, those with a high-risk profile for events but low susceptibility to atherosclerosis may never have events or may only have events late in life. This clinical reality is driven by the observation that the level of exposure to the drivers of atherosclerosis (i.e., the traditional risk factors for cardiovascular disease) is only marginally different between those who will have an adverse cardiovascular event and those who will not. ${ }^{16}$ Despite these qualifications and limitations, the currently available risk-prediction models for cardiovascular events, which primarily assess an individual's exposure to the drivers of atherosclerosis, correctly predict about $70 \%$ of subsequent cardiovascular events in both individuals and populations..$^{29-31,33,34}$ As new data and research become available, the incorporation of susceptibility markers to atherosclerosis, such as biochemical markers, anatomic markers from imaging studies and genetic information, may help to substantially improve the discrimination, calibration and reclassification abilities of these risk models for cardiovascular disease.

\section{Treatment targets}

Many of the treatment targets are individualized according to risk. In general, the higher the absolute risk, the greater the need for more aggressive treatment targets. In a patient at high risk for cardiovascular disease, the priority for intervention should focus on reduction of the risk factors that can most effectively modify the natural history for that patient. For example, in a patient with increased cardiometabolic risk, effective reduction of blood pressure in the short term will be a high priority to reduce future events, whereas reducing weight and increasing physical activity will be important in the long run. ${ }^{7.8}$ The importance of quitting smoking will always remain paramount among smokers.

\section{Health behaviour interventions}

At the core of healthy behaviours is the achievement and maintenance of clinically appropriate changes to behaviour. To achieve long-term changes, health care practitioners need to engage patients in a purposeful process that encourages them to make small but progressive positive changes in their health behaviours. Meta-analytic research in this area indicates that the most successful and long-lasting interventions are those that are practical, appeal to patients on an emotional basis and and are reinforced by positive social interactions. ${ }^{40}$

All patients should adopt and adhere to healthy behaviours, including not smoking and following a diet capable of promoting energy balance and the maintenance of a healthy body weight. Dietary sodium intake should be maintained under the upper limit of $2300 \mathrm{mg}$ as outlined in Box 3. For overweight and obese patients, a negative energy balance is required for weight loss. Heart-healthy or vascular- 
friendly diets are those that are low in saturated fat, include at least five servings of fruits and vegetables per day, contain little or no processed carbohydrates and minimize or eliminate the intake of protein from animal sources. Healthy behaviours with respect to physical activity include the accumulation of at least 150 minutes of moderate to vigorous physical activity per week in bouts of 10 minutes or more. Societal and environmental determinants of health behaviours are powerful forces that may promote or degrade a patient's health and should be a focus of concerted public health activity.

\section{Pharmacologic therapy}

Pharmacologic therapy should be tailored to the patient's level of risk, specific risk factor target, and clinical profile in terms of co-existing condi-

\begin{tabular}{|c|c|c|c|c|}
\hline \multirow[b]{2}{*}{ Characteristic } & \multirow{2}{*}{$\begin{array}{l}\text { Framingham Risk Score }{ }^{30} \\
\qquad n=8491\end{array}$} & \multirow{2}{*}{$\begin{array}{c}\text { Systematic Coronary Risk } \\
\text { Evaluation (SCORE) }^{31} \\
n=205178\end{array}$} & \multicolumn{2}{|c|}{ Reynolds Risk Score } \\
\hline & & & Women $^{32} n=24558$ & $\operatorname{Men}^{39} n=10274$ \\
\hline Patient age, yr (mean) $\dagger$ & 30-74 (49) & $19-80(46)$ & $35-65$ (47) & $>45(52)$ \\
\hline Mean follow-up, yrł & 12 & 13 & 10.2 & 10.8 \\
\hline Risk factors considered & $\begin{array}{l}\text { Age; sex (F or } \mathrm{M}) \text {; total } \\
\text { cholesterol; } \mathrm{HDL} \text {; } \\
\text { smoking status; systolic } \\
\text { blood pressure; } \\
\text { diabetes; treatment for } \\
\text { hypertension }\end{array}$ & $\begin{array}{l}\text { Age; sex (F or M); total } \\
\text { cholesterol; HDL; } \\
\text { smoking; systolic blood } \\
\text { pressure }\end{array}$ & $\begin{array}{l}\text { Age; sex (F); total } \\
\text { cholesterol; HDL; } \\
\text { smoking status; systolic } \\
\text { blood pressure; } \\
\text { hemoglobin } \mathrm{A}_{1 \mathrm{C}} \text { (if } \\
\text { diabetes); high- } \\
\text { sensitivity C-reactive } \\
\text { protein; parental } \\
\text { history of } \mathrm{Ml}<60 \mathrm{yr}\end{array}$ & $\begin{array}{l}\text { Age; sex }(\mathrm{M}) \text {; total } \\
\text { cholesterol; } \mathrm{HDL} ; \\
\text { smoking status; systolic } \\
\text { blood pressure; } \\
\text { hemoglobin } \mathrm{A}_{1 \mathrm{c}} \\
\text { (if diabetes); } \\
\text { high-sensitivity } \\
\text { C-reactive protein; } \\
\text { parental history of MI } \\
<60 \mathrm{yr}\end{array}$ \\
\hline Outcomes & $\begin{array}{l}\text { MI; cardiac death; } \\
\text { coronary insufficiency; } \\
\text { angina; ischemic stroke; } \\
\text { hemorrhagic stroke; } \\
\text { transient ischemic } \\
\text { attack; peripheral } \\
\text { artery disease; heart } \\
\text { failure }\end{array}$ & $\begin{array}{l}\text { Fatal coronary artery } \\
\text { disease }\end{array}$ & $\begin{array}{l}\text { Ml; ischemic stroke; } \\
\text { coronary } \\
\text { revascularization; } \\
\text { cardiovascular death } \\
\text { (congestive heart } \\
\text { disease and } \\
\text { cardiovascular disease } \\
\text { combined) }\end{array}$ & $\begin{array}{l}\text { Ml; stroke; coronary } \\
\text { revascularization; } \\
\text { cardiovascular death } \\
\text { (congestive heart } \\
\text { disease and } \\
\text { cardiovascular disease } \\
\text { combined) }\end{array}$ \\
\hline Advantages & $\begin{array}{l}\text { Widely recognized; } \\
\text { simple; paper and } \\
\text { online versions }\end{array}$ & $\begin{array}{l}\text { Very large population; } \\
\text { country-specific } \\
\text { calibration (SCORE } \\
\text { Canada) is available; } \\
\text { diverse ethnicity; } \\
\text { application for } \\
\text { management of risk } \\
\text { factors; paper and online } \\
\text { versions }\end{array}$ & $\begin{array}{l}\text { High-sensitivity } \\
\text { C-reactive protein } \\
\text { levels may suggest } \\
\text { susceptibility to } \\
\text { cardiovascular disease; } \\
\text { short- and long-term } \\
\text { risk; online risk } \\
\text { algorithm more } \\
\text { accurate than print } \\
\text { tables; included family } \\
\text { history }\end{array}$ & $\begin{array}{l}\text { High-sensitivity } \\
\text { C-reactive protein } \\
\text { levels may suggest } \\
\text { susceptibility to } \\
\text { cardiovascular disease; } \\
\text { short- and long-term } \\
\text { risk; online risk } \\
\text { algorithm more } \\
\text { accurate than print } \\
\text { tables; included family } \\
\text { history }\end{array}$ \\
\hline Challenges & $\begin{array}{l}\text { Relatively small sample } \\
\text { size; limited ethnicity; } \\
\text { family history not } \\
\text { included }\end{array}$ & $\begin{array}{l}\text { Not well known in } \\
\text { Canada; effect of } \\
\text { physical (in)activity levels } \\
\text { on cardiovascular risk } \\
\text { may be different in } \\
\text { Canada than in Europe; } \\
\text { only outcome measured } \\
\text { is death from coronary } \\
\text { artery disease; family } \\
\text { history not included }\end{array}$ & $\begin{array}{l}\text { Not well known; online } \\
\text { only }\end{array}$ & $\begin{array}{l}\text { Not well known; online } \\
\text { only }\end{array}$ \\
\hline URL for risk calculator & $\begin{array}{c}\text { www.framinghamheart } \\
\text { study.org/risk/gencardio } \\
\text {.html }\end{array}$ & $\begin{array}{l}\text { www.heartscore.org/Pages } \\
\text { /welcome.aspx }\end{array}$ & www.reynold & riskscore.org \\
\hline
\end{tabular}


tions. It is most important to follow up with patients to ensure that the pharmacologic therapy has achieved the treatment target in a timely manner, without excessive adverse effects or drug interactions. Once again, all risk factors for cardiovascular disease need to be treated to target to maximize the clinical potential for reducing the risk of cardiovascular events. A combination of modifications to health behaviours and pharmacologic interventions will be required in most patients at high and moderate risk of cardiovascular events to meet treatment targets.

\section{Implementation}

The C-CHANGE Initiative purposefully involved implementation experts and integrated implementation strategies into all of their deliberations on harmonized recommendations. This proactive focus on implementation recognizes that there are important gaps and opportunities to enhance use of guidelines and to improve practice. ${ }^{41-43}$ The broader literature on guideline implementation includes two types of strategies: extrinsic (targeting the practice environment through educational or organizational interventions) and intrinsic (modifying the guideline itself).

A large meta-analysis of extrinsic strategies found a modest positive effect on implementation but widely varying costs and impact. ${ }^{44} \mathrm{Ex}$ trinsic strategies that focus on physicians as the primary target for intervention include more education for physicians and patients, and better availability of guidelines. ${ }^{42}$ Intrinsic strategies, which guideline producers themselves can adopt, are inexpensive and can be incorporated into the development process. ${ }^{44}$ The intrinsic strategies to be used by the C-CHANGE Initiative will include the use of a guideline implementability tool to optimize desirable characteristics such as simplicity, actionability, clarity and contextual framing. ${ }^{42,45}$ The effectiveness of this approach will be tested by assessing the impact of source versus harmonized recommendations on decision-making using clinical vignettes in a controlled trial. ${ }^{46}$ The C-CHANGE Initiative will also use extrinsic implementation strategies, such as national peer-led interactive educational sessions tailored to the needs of front-line clinicians in different regions. This approach builds local capacity, is widely replicable and allows for evaluation, in a randomized controlled design, against standardized training.

With respect to additional implementation opportunities, efforts are being expended to develop multiple information platforms such as Web-based case studies, smart phone applications and peer tutoring materials. The C-
CHANGE Initiative will work with vendors of electronic medical records to develop computerized decision-support systems that embed clinical practice recommendations within patient-care software and test the impact of this intervention in a controlled design. This strategy is promising because it provides comprehensive input at the point of care, which directly addresses the issue of availability and simplicity ${ }^{47}$ In addition, the CCHANGE Initiative will track changes in prescription patterns before and after guideline release, analyzing databases such as the Intercontinental Medical Statistics CompuScript database ${ }^{48}$ and establish partnerships with research networks based in primary care practice to assess other changes in practice using interrupted time series designs.

The implementation strategy of the CCHANGE Initiative also proposes an outcomes evaluation plan allowing for tracking of clinical and health system outcomes. Major adverse cardiovascular events will be tracked through the integration and analysis of anonymized data from national and regional databases. By focusing on outcomes as an integral, not optional, component of implementation, the C-CHANGE Initiative further underscores the critical clinical and economic importance of objectively assessing the impact of clinical practice guidelines and recommendations. Without such objective assessments, the positive impact of guidelines for disease prevention and chronic care on population or individual health may be substantially overestimated, and the potential harm patients are exposed to may be substantially underestimated.

\section{Future challenges and opportunities}

The process of developing this first set of harmonized guidelines has raised many questions: What is the best strategy for grading evidence for all of the guidelines? What are the ideal principles underpinning the harmonization process? What are the key steps and overall models that would successfully promote the adoption of ideals and principles? What recommendations warrant the highest priority? How do we achieve the best wording of recommendations to improve the uptake of recommendations? How will quality indicators of health systems and patient care evolve as a result of harmonized guidelines? What are the most clinically effective implementation strategies for all clinical practice guidelines and recommendations? These questions will form the foundation for further scientific enquiry. 
The harmonization process has also identified a number of research opportunities regarding the development and implementation of guidelines: How do we tailor guidelines and practice recommendations to best serve ethnic, vulnerable and region-specific populations? How do we eliminate system barriers to clinically effective patient care? How can those involved in education communicate the benefits and advantages of evidence-informed, guideline-based patient care? How do we extend the evidence-based approach to harmonization and integration of guidelines for other comorbidities, such as depression and musculoskeletal disorders?

Ultimately, future iterations of the CCHANGE Initiative will endeavour to address these challenges and many other research questions. The gaps in knowledge, along with the existing and potential gaps in treatment, identified through this harmonization process provide a distinct opportunity to align and integrate guidelines for the management of chronic disease in a manner that effectively consolidates, rather than confuses, routine patient care.

\section{References}

1. Wijeysundera HC, Machado M, Farahati F, et al. Association of temporal trends in risk factors and treatment uptake with coronary heart disease mortality, 1994-2005. JAMA 2010;303:1841-7.

2. Canadian Diabetes Association Clinical Practice Guidelines Expert Committee. Canadian Diabetes Association 2008 clinical practice guidelines for the prevention and management of diabetes in Canada. Can J Diabetes 2008;32(Suppl 1):S1-201.

3. Genest J, McPherson R, Frohlich J, et al. 2009 Canadian Cardiovascular Society/Canadian guidelines for the diagnosis and treatment of dyslipidemia and prevention of cardiovascular disease in the adult - 2009 recommendations. Can J Cardiol 2009;25:567-79.

4. Quinn RR, Hemmelgarn BR, Padwal RS, et al. The 2010 Canadian Hypertension Education Program recommendations for the management of hypertension: part I — blood pressure measurement diagnosis and assessment of risk. Can J Cardiol 2010;26:241-8.

5. Stone JA, Austford L, Parker JH, et al. AGREEing on Canadian cardiovascular clinical practice guidelines. Can J Cardiol 2008;24:753-7.

6. Grol R. Successes and failures in the implementation of evidencebased guidelines for clinical practice. Med Care 2001;39:II46-54.

7. Leiter LA, Fitchett DH, Gilbert RE, et al. Cardiometabolic risk in Canada: a detailed analysis and position paper by the cardiometabolic risk working group. Can J Cardiol 2011;27:e1-33.

8. Hackam DG, Khan NA, Hemmelgarn BR, et al. The 2010 Canadian Hypertension Education Program recommendations for the management of hypertension: part 2 - therapy. Can J Cardiol 2010;26:249-58.

9. Lau DC, Douketis JD, Morrison KM, et al. 2006 Canadian clinical practice guidelines on the management and prevention of obesity in adults and children [summary]. CMAJ 2007;176:S1-13.

10. Stone JA, Arthur HM, Suskin NG, editors. Canadian Association of Cardiac Rehabilitation national guidelines for cardiac rehabilitation and cardiovascular disease prevention. $3 \mathrm{rd} \mathrm{ed}$. Winnipeg (MB): Canadian Association of Cardiac Rehabilitation; 2009

11. Warburton DE, Charlesworth S, Ivey A, et al. A systematic review of the evidence for Canada's physical activity guidelines for adults. Int J Behav Nutr Phys Act 2010;7:39.

12. Gartlehner G. Evidence-based medicine breaking the borders a working model for the European Union to facilitate evidencebased health care. Wien Med Wochenschr 2004;154:127-32.

13. Schünemann HJ, Woodhead M, Anzueto A, et al. A vision statement on guideline development for respiratory disease: the example of COPD. Lancet 2009;373:774-9.

14. Michie S, Johnston M. Changing clinical behaviour by making guidelines specific. BMJ 2004;328:343-5.
15. Lindsay P, Bayley M, McDonald A, et al. Toward a more effective approach to stroke: Canadian best practice recommendations for stroke care. CMAJ 2008; 178:1418-25.

16. van Dis I, Kromhout D, Geleijnse JM, et al. Evaluation of cardiovascular risk predicted by different SCORE equations: the Netherlands as an example. Eur J Cardiovasc Prev Rehabil 2010; 17:244-9.

17. New Zealand Guidelines Group. Evidence-based best practice guideline. The assessment and management of cardiovascular risk Wellington (NZ): The Group; 2003. Available: www.nzgg.org .nz/resources/33/CVC_Risk_Full.pdf (accessed 2011 Aug. 11).

18. Crooke M. New Zealand cardiovascular guidelines: best practice evidence-based guideline: the assessment and management of cardiovascular risk December 2003. Clin Biochem Rev 2007;28:19-29.

19. World Health Organization. Prevention of cardiovascular disease: pocket guidelines for assessment and management of cardiovascular risk. Geneva: The Organization; 2007. Available: www.who.int/cardiovascular_diseases/guidelines/PocketGL.EN GLISH.AFR-D-E.rev1.pdf (accessed 2011 Aug. 30).

20. Schulz KF, Altman DG, Moher D. CONSORT 2010 statement: updated guidelines for reporting parallel group randomized trials. Ann Intern Med 2010;152:726-32.

21. Redelmeier DA, Tan SH, Booth GL. The treatment of unrelated disorders in patients with chronic medical diseases. $N$ Engl J Med 1998;338:1516-20.

22. Burge FI, Bower K, Putnam W, et al. Quality indicators for cardiovascular primary care. Can J Cardiol 2007;23:383-8.

23. Lewanczuk R. Innovations in primary care: implication for hypertension detection and treatment. Can J Cardiol 2006;22:614-6.

24. Brouwers MC, Kho ME, Browman GP, et al. AGREE II: advancing guideline development, reporting and evaluation in health care. CMAJ 2010;182:E839-42.

25. AGREE Collaboration. Development and validation of an international appraisal instrument for assessing the quality of clinical practice guidelines: the AGREE project. Qual Saf Health Care 2003; 12:18-23.

26. Ward V, House A, Hamer S. Developing a framework for transferring knowledge into action: a thematic analysis of the literature. J Health Serv Res Policy 2009;14:156-64.

27. Tobe SW, Touyz RM, Campbell NR. The Canadian Hypertension Education Program - a unique Canadian knowledge translation program. Can J Cardiol 2007;23:551-5.

28. Eating well with Canada's food guide. Ottawa $(\mathrm{ON})$ : Health Canada; 2007. Available: www.hc-sc.gc.ca/fn-an/alt_formats /hpfb-dgpsa/pdf/food-guide-aliment/view_eatwell_vue_bien mang-eng.pdf (accessed 2011 Aug. 11).

29. Greenland P, Alpert JS, Beller GA, et al. 2010 ACCF/AHA guideline for assessment of cardiovascular risk in asymptomatic adults: a report of the American College of Cardiology Foundation/American Heart Association Task Force on Practice Guidelines. J Am Coll Cardiol 2010;56:e50-103.

30. D'Agostino RB Sr, Vasan RS, Pencina MJ, et al. General cardiovascular risk profile for use in primary care: the Framingham Heart Study. Circulation 2008;117:743-53.

31. Conroy RM, Pyorala K, Fitzgerald AP, et al. Estimation of tenyear risk of fatal cardiovascular disease in Europe: the SCORE project. Eur Heart J 2003;24:987-1003.

32. Ridker PM, Buring JE, Rifai N, et al. Development and validation of improved algorithms for the assessment of global cardiovascular risk in women: the Reynolds Risk Score. JAMA 2007;297:611-9.

33. Ware JH. The limitations of risk factors as prognostic tools N Engl J Med 2006;355:2615-7.

34. Tunstall-Pedoe H. Cardiovascular risk and risk scores: ASSIGN, Framingham, QRISK and others: how to choose. Heart 2011;97: $442-4$.

35. Stone JA. Framing cardiovascular disease event risk prediction Can J Cardiol 2011;27:171-3

36. Erbel R, Mohlenkamp S, Moebus S, et al. Coronary risk stratification, discrimination, and reclassification improvement based on quantification of subclinical coronary atherosclerosis: the Heinz Nixdorf Recall study. J Am Coll Cardiol 2010;56:1397-406.

37. Sharman JE, Prins JB. Strengthening the case for global risk assessment of patients with high blood pressure. Am J Hypertens 2009;22:9.

38. Poulter N. Global risk of cardiovascular disease. Heart. 2003; 89(Suppl 2):ii2-5; discussion ii35-7.

39. Ridker PM, Paynter NP, Rifai N, et al. C-reactive protein and parental history improve global cardiovascular risk prediction: the Reynolds Risk Score for men. Circulation 2008;118:2243-51.

40. DiMatteo MR. Social support and patient adherence to medical treatment: a meta-analysis. Health Psychol 2004;23:207-18.

41. Kedward J, Dakin L. A qualitative study of barriers to the use of statins and the implementation of coronary heart disease prevention in primary care. Br J Gen Pract 2003;53:684-9. 
42. Hobbs FD, Erhardt L. Acceptance of guideline recommendations and perceived implementation of coronary heart disease prevention among primary care physicians in five European countries: the Reassessing European Attitudes about Cardiovascular Treatment (REACT) survey. Fam Pract 2002;19:596-604.

43. Putnam W, Twohig PL, Burge FI, et al. Evidence-based cardiovascular care. Family physicians' views of obstacles and opportunities. Can Fam Physician 2004;50:1397-405.

44. Grimshaw JM, Thomas RE, MacLennan G, et al. Effectiveness and efficiency of guideline dissemination and implementation strategies. Health Technol Assess 2004;8:iii-iv, 1-72.

45. Shiffman RN, Dixon J, Brandt C, et al. The GuideLine Implementability Appraisal (GLIA): development of an instrument to identify obstacles to guideline implementation. BMC Med Inform Decis Mak 2005;5:23.

46. Kastner M, Estey E, Bhattacharyya O. Better guidelines for better care: enhancing the implementability of clinical practice guidelines. Expert Rev Pharmacoecon Outcomes Res 2011;11:315-24.

47. Jaspers MW, Smeulers M, Vermeulen H, et al. Effects of clinical decision-support systems on practitioner performance and patient outcomes: a synthesis of high-quality systematic review findings. J Am Med Inform Assoc 2011;18:327-34.

48. Hemmelgarn BR, Chen G, Walker R, et al. Trends in antihypertensive drug prescriptions and physician visits in Canada between 1996 and 2006. Can J Cardiol 2008;24:507-12.

Competing interests: Sheldon Tobe has received grants from Baxter, Janssen-Ortho, Novartis, Pfizer, Merck, AstraZeneca and Amgen; consulting fees or honoraria, or payment for lectures or educational presentations, from Pfizer, Bristol-Myers Squibb-Sanofi-aventis, Merck and Abbott; and support for travel to meetings for the study or other purposes from Bristol-Myers Squibb-Sanofi-aventis, Merck, Pfizer, AstraZeneca, Abbott and Boehringer Ingelheim. James Stone has received consulting fees and payment for lectures or development of educational presentations from AstraZeneca, Merck, Novartis, Pfizer and Servier; payment for manuscript preparation from the Cardio-Metabolic Research Group. His institution has received grants or has grants pending from the Canadian Institutes of Health Research. None declared by Melissa Brouwers. Onil Bhattacharyya has received funds through an Ontario Ministry of Health and Long-Term Care Career Scientist Award. None declared by Kimberly Walker. Martin Dawes has received funds from Health Canada for travel. Jacques Genest Jr. has received consulting fees or honoraria, or payment for development of educational presentations from Amgen, Merck, AstraZeneca and Pfizer. Steven Grover has received funds as a board member of or consulting fees for Merck, Pfizer and AstraZeneca; has provided expert testimony for Otsuka; and has grants or grants pending from Otsuka and Merck. Gordon Gubitz has received payment for lectures from Boehringer Ingelheim and Sanofi. David Lau has received consulting fees or speaker's honoraria, payment for lectures or has grants or grants pending from Abbott, Allergan, AstraZeneca, Bristol-Myers Squibb, Boehringer Ingelheim, Eli Lilly, Merck, Pfizer and Sanofi-aventis. He has received payment from AstraZeneca for development of lipid education programs. He has given expert testimony or reports to the Canadian Medical Protective Association. Andrew Pipe has received funds as a board member for Pfizer, Johnson \& Johnson and GlaxoSmithKline; fees for educational presentations from Pfizer and Johnson \& Johnson; payment for manuscript preparation from Snell Publications and Parkhurst Exchange; payment for development of educational materials for Pfizer; and honoraria from a variety of government and voluntary health organizations, hospitals and medical organizations for the preparation of reports and the development and delivery of educational presentations. Peter Selby has received funds as a board member for or consulting fees from Schering Canada, Johnson \& Johnson, Consumer Healthcare Canada, Pfizer, Sanofi-Synthelabo Canada, GlaxoSmithKline, Genpharm, Prempharm, Nabi Bioharmaceuticals, V-CC Systems, Inc. and eHealth Behaviour Change Software Co. He has received payment for lectures or development of educational presentations from Pfizer and Johnson \& Johnson. His institution has grants or grants pending from Centre for Addiction and Mental Health; Ontario Ministry of Health Promotion;
Tobacco Control Program, Health Canada; National Institute on Drug Abuse; Cancer Care Ontario; Pfizer; Canadian Tobacco Control Research Initiative; Canadian Institutes for Health Research; Vancouver Coastal Health; and Alberta Health Services (formerly Alberta Cancer Board). Mark Tremblay has been paid by various entities to give keynote addresses related to physical activity (see Appendix 2, available at www.cmaj.ca/lookup/suppl/doi:10.1503/cmaj.101508 /-/DC1, for a list of the entities). None declared by Darren Warburton. Richard Ward has received consulting fees, payment for lectures or payment for development of educational presentations from Pfizer, AstraZeneca, Boehringer Ingelheim, Eli Lilly and Sanofi-aventis. Vincent Woo has received consulting fees or honoraria, or payment for lectures from AstraZeneca, Bristol-Myers Squibb, Abbott, Novo Nordisk, Eli Lilly, Sanofi-aventis, Boehringer Ingelheim and Merck. Lawrence Leiter has received consulting fees or honoraria, or has grants or grants pending from AstraZeneca, Merck, Pfizer, Roche, Abbott, Bristol-Myers Squibb, Boehringer Ingelheim, Eli Lilly, GlaxoSmithKline, Novartis, Novo Nordisk, Sanofiaventis and Servier. Peter Liu has grants or grants pending from Pfizer, Servier and Novartis. He was director of the Institute of Circulatory and Respiratory Health at CIHR at the beginning of the project, but most of the manuscript writing was done following completion of his term at CIHR. Conflict of Interest Management and Central Review Committee: To address conflicts of interest, each member of the C-CHANGE Guideline Panel declared all sources of funding and all real or potential conflicts of interest. This approach has allowed the development of a plan that has ensured competing interests were managed at every level of the program. The Central Review Committee is composed of methodologic experts who are free from all conflicts of interest, who can ensure the evidence is critically appraised and graded consistently.

Affiliations: From the Division of Nephrology (Tobe), Sunnybrook Health Sciences Centre, University of Toronto, Toronto, Ont.; the University of Calgary, the Libin Cardiovascular Institute of Alberta and the Cardiac Wellness Institute of Calgary (Stone), Calgary, Alta.; the Departments of Oncology and of Clinical Epidemiology and Biostatistics (Brouwers), McMaster University, Hamilton, Ont.; the Department of Family and Community Medicine, Li Ka Shing Knowledge Institute of St. Michael's Hospital (Bhattacharyya), University of Toronto, Toronto, Ont.; the Institute of Circulatory and Respiratory Health, Canadian Institutes of Health Research (Walker), Ottawa, Ont; the Department of Family Medicine (Dawes), University of British Columbia, Vancouver, BC; the Departments of Medicine (Genest), and Clinical Epidemiology (Grover), McGill University, Montréal, Que.; the Department of Medicine (Gubitz), Dalhousie University, Halifax, NS; the Departments of Medicine and of Biochemistry and Molecular Biology (Lau), University of Calgary, Calgary, Alta.; the Minto Prevention and Rehabilitation Centre, University of Ottawa Heart Institute (Pipe), Ottawa, Ont.; the Centre for Addiction and Mental Health (Selby), University of Toronto, Toronto, Ont.; the Children's Hospital of Eastern Ontario Research Institute (Tremblay), Ottawa, Ont.; the Cardiovascular Physiology and Rehabilitation Laboratory (Warburton), Experimental Medicine Program, University of British Columbia, Vancouver, BC; the Department of Family Medicine (Ward), University of Calgary, Calgary, Alta.; the Section of Endocrinology, Health Sciences Centre (Woo), University of Manitoba, Winnipeg, Man.; the Keenan Research Centre, Li Ka Shing Knowledge Institute of St. Michael's Hospital (Leiter), University of Toronto, Toronto, Ont.; the Heart and Stroke/Richard Lewar Centre and Peter Munk Cardiac Centre, University Health Network (Liu), University of Toronto, Toronto, Ont.

Contributors: James Stone, Sheldon Tobe and Peter Liu were involved in the original creation of the C-CHANGE group, all versions of the manuscript and all manuscript reviews. Sheldon Tobe was also responsible for methodology and harmonization. Onil Bhattacharyya contributed to the 
initial design, reviewed the drafts and made comments, wrote and revised the section on the implementation strategy, and read and approved revised versions of the document. Kimberly Walker worked on harmonization methodology and process, and wrote and reviewed sections of the manuscript. Melissa Brouwers worked on harmonization methodology, and wrote and reviewed sections of the manuscript. Martin Dawes, Jacques Genest, Steven Grover, Gordon Gubitz, David Lau, Andrew Pipe, Peter Selby, Mark Tremblay, Darren Warburton, Richard Ward, Vincent Woo and Lawrence Leiter were involved in the meetings to select the clinical practice recommendations contained within this document. They were also involved in editing, reviewing and critiquing each version of this manuscript.

Funding: The development of harmonized guidelines was funded entirely from public or government sources. The Institute of Circulatory and Respiratory Health (ICRH) at the CIHR provided some unrestricted seed funding to start the C-CHANGE harmonization process, through the institute's knowledge translation program. This was complemented by a contribution grant and in-kind support from staff from the Public Health Agency of Canada. The support from ICRH and the Public Health Agency of Canada was part of their commitment to the federal government's Canadian Heart Health Strategy recommendation. Other public or government sources of funding include Cardiac Care Network of Ontario and Ontario Ministry of Health and LongTerm Care. The following grants were associated with this project: Ministry of Health and Long-Term Care Alternative Funding Plans Innovation Grant and Public Health Agency of Canada no. 6282-15-2010/3381084. The funders did not have a direct influence on the process or contents of the recommendations or the preparation of the manuscripts. Peter Liu, the former scientific director of ICRH, did not participate in the manuscript writing until the completion of his term at ICRH.

Acknowledgements: The C-CHANGE executive acknowledges the insightful advice, wisdom and enthusiastic support of the following people: Dr. Heather Arthur, Dr. Norm Campbell, Dr. Denis Drouin, Dr. Rene Gagnon, Dr. Ross Feldman, Dr. George Fodor, Dr. Norm Gledhill, Dr. Stewart Harris, Dr. Mike Sharratt, Dr. Eldon Smith, Dr. Guy Tremblay, Ms Katherine Gardner, Mr. Tim Hutchinson, Mr. James Kavanagh, Ms Tina Lawton and Ms Laura Syron. 